\title{
Preliminary Cleaning Tests on Candidate Materials for APS Beamline and Front End UHV Components
}

\author{
R. Nielsen and T. M. Kuzay
}

\section{DISCLAIMER}

This report was prepared as an account of work sponsored by an agency of the United States Government. Neither the United States Government nor any agency thereof, nor any of their employees, makes any warranty, express or implied, or assumes any legal liability or responsibility for the accuracy, completeness, or usefulness of any information, apparatus, product, or process disclosed, or represents that its use would not infringe privately owned rights. Reference herein to any specific commercial product, process, or service by trade name, trademark, manufacturer, or otherwise does not necessarily constitute or imply its endorsement, recommendation, or favoring by the United States Government or any agency thereof. The views and opinions of authors expressed herein do not necessarily state or reflect those of the United States Government or any agency thereof.

May 12, 1992

\section{Experimental Facilities Division Advanced Photon Source Argonne National Laboratory}




\section{DISCLAIMER}

Portions of this document may be illegible in electronic image products. Images are produced from the best available original document. 


\title{
Preliminary Cleaning Tests On Candidate Materials for APS Beamline and Front End UHV Components
}

\author{
R. W. Nielsen \& T. M. Kuzay
}

Introduction

Comparative cleaning tests have been done on four candidate materials for use in APS beamline and front-end vacuum components. These materials are 304 SS, 304L SS, OFHC copper, and Glidcop* $\left(\mathrm{Cu}-\mathrm{Al}_{2} \mathrm{O}_{3}\right)$. Samples of each material were prepared and cleaned using two different methods. After cleaning, the sample surfaces were analyzed using ESCA (Electron Spectography for Chemical Analysis). Uncleaned samples were used as a reference. The cleaning methods and surface analysis results are further discussed.

\section{Cleaning Methods}

The first cleaning method consisted of conventional chemical cleaning in trichlorethane, acetone, and ethyl alcohol. Samples were ultrasonically cleaned in each chemical for 15 minutes at room temperature.

The second cleaning method is a new technique not previously explored for UHV applications[1]. A remote variation of this technique using $\mathrm{CO}_{2}$ snow as a high velocity jet to clean vacuum surfaces has been known [2]. The new technique consists of supercritical fluid cleaning using $\mathrm{CO}_{2}$. Samples were taken to the Liquid Carbonic Supercritical Processing Facility in Allentown, Pennsylvania, where two cleaning runs at different pressures were completed.

Cleaning in chemical solvents consists essentially of dissolving the contaminants and flushing them from the surface using turbulence. Supercritical cleaning relates to the properties of gas liquification. If a pure gas is compressed below a "critical temperature," liquification occurs. At temperatures above this "critical temperature," no liquification is possible regardless of the pressure applied. Fig. 1 is a phase diagram of a typical supercritical fluid. For $\mathrm{CO}_{2}$, the critical temperature is $31^{\circ} \mathrm{C}$, and the critical pressure is $1073 \mathrm{psi}$.

As the pressure is increased, the gas density is increased to near liquid densities where the supercritical fluid displays good solubilizing properties. The

\footnotetext{
* Trademark, SCM Metal Products Inc., NC
} 
cleaning effectiveness of supercritical $\mathrm{CO}_{2}$ is dependent on the temperature, pressure, flow rate, turbulence, and time the materials to be cleaned remain in the media.

Supercritical cleaning in $\mathrm{CO}_{2}$ has many attractive characteristics. $\mathrm{CO}_{2}$ is readily available, inexpensive, non-flammable, non-toxic, and non-halogenated. Most important, it is a naturally occurring, environmentally safe gas. Its use for cleaning would eliminate the expense and documentation required for disposal of toxic spent cleaning chemicals.

Fig. 2 is a schematic of a supercritical cleaning system [3]. The material to be cleaned is placed in the cleaning vessel, which is then sealed and purged with low pressure $\mathrm{CO}_{2}$ gas. Gas recycled from the separator stage is sent through high pressure pumps to a heat exchanger to reach the operating pressure and temperature within the supercritical fluid region. The supercritical fluid then passes through the cleaning vessel where various mixing or agitating means promote intimate contact with the material to be cleaned. After passing through the cleaning vessel, the $\mathrm{CO}_{2}$ pressure and temperature are adjusted to allow separation of organic materials from the $\mathrm{CO}_{2}$ (now a gas) in the separator stage. The cycle is then repeated in a closed loop, and the $\mathrm{CO}_{2}$ is recycled through the system.

The single pass mode was used to clean the samples for this test. In this mode, the $\mathrm{CO}_{2}$ is converted to supercritical conditions as in the closed-loop mode, but, after passing through the cleaning vessel, it is returned to the gas phase and exhausted to the atmosphere.

Two runs were completed with the supercritical fluid process. The parameters of the first run were 3500 psi cleaning vessel pressure at $45^{\circ} \mathrm{C}$ with a velocity through the vessel of $1.4 \mathrm{~cm} / \mathrm{min}$. The parameters of the second run were $2000 \mathrm{psi}$ cleaning vessel pressure at $45^{\circ} \mathrm{C}$ with a velocity through the vessel of $1.6 \mathrm{~cm} / \mathrm{min}$.

\section{Surface Analysis}

Analysis of uncleaned sample surfaces proved the SS samples much more contaminated with hydrocarbons than the copper or Glidcop samples. The uncleaned SS surfaces showed only $\mathrm{C}, \mathrm{O}$, and $\mathrm{Na}$ with no traces of iron or chromium. Uncleaned copper and Glidcop surfaces contained $\mathrm{C}, \mathrm{O}, \mathrm{Si}$, and reasonable traces of copper.

The chemically cleaned samples produced the "cleanest" surfaces with 
approximately $1 \% \mathrm{C}$ on the SS surfaces and $<1 \% \mathrm{C}$ remaining on the copper and Glidcop surfaces.

Figs. 3-6 are sample ESCA profiles for each of the materials tested. Several plots such as this were done for each sample. In order to compress the data to an easier to understand format, all ESCA data were converted to atomic elemental percentages as shown in Fig. 7.

The surfaces of the supercritically cleaned SS samples contained a C residue of approximately 5.5 to $7 \%$ in comparison to $1 \%$ on the chemically cleaned samples. There were also traces of $\mathrm{Ca}$ and $\mathrm{Na}$ that were removed with chemical cleaning but not removed (1 $-5 \%)$ with supercritical cleaning.

In the case of the copper and Glidcop, the $\mathrm{C}$ residue for the supercritically cleaned samples was $2-4 \%$ in comparison to $<1 \%$ for the chemically cleaned samples. Traces of $\mathrm{Si}$ were detected in the supercritically cleaned samples but were not detected in the chemically cleaned samples.

\section{Conclusions}

The results of both runs using the supercritical fluid process were very similar with perhaps a slight superiority in the second run. This seems somewhat contradictory to what would be expected since the pressure in the first run was higher, which means that the $\mathrm{CO}_{2}$ density was higher. The velocity through the vessel was slightly greater in the second run, which could have created more turbulence and slightly better cleaning. The turbulence was minimal in both runs due to the low solvent velocities.

Considering the low solvent velocities, the cleaning results are impressive. Plans are underway for an additional supercritical cleaning run with higher flow rates and turbulence supplied by either an impeller or ultrasonics in an attempt to equal or exceed the chemical cleaning results. Additionally, thermal and photon induced desorption measurements will be conducted on the samples in a synchrotron facility.

\section{Acknowledgments}

This work was supported by the U. S. Department of Energy, Experimental Facilities, Advanced Photon Source, under contract W-31-109Eng-38.

The interest and efforts of Mr. Raymond Robey and Mr. Richard Wildasin from the Supercritical Processing Group of Liquid Carbonic are greatly 
appreciated for supplying the equipment and expertise to do the supercritical cleaning.

Appreciation is also expressed to Dr. John Gavrilovic from McCrone Associates who carried out the ESCA analysis under contract and added greatly to the understanding of the results.

\section{References}

1. Introduction to Supercritical Cleaning, Report by Liquid Carbonic, Supercritical Processing Group, Allentown, PA.

2. L. Layden and D. Wadlow, "High Velocity $\mathrm{CO}_{2}$ Snow for Cleaning Vacuum System Surfaces," J. Vac. Sci. Tech., A8(5), Sept/Oct. 1990.

3. Qualifications Manual for Supercritical Cleaning, Report by Liquid Carbonic, Supercritical Processing Group, Allentown, PÁ. 


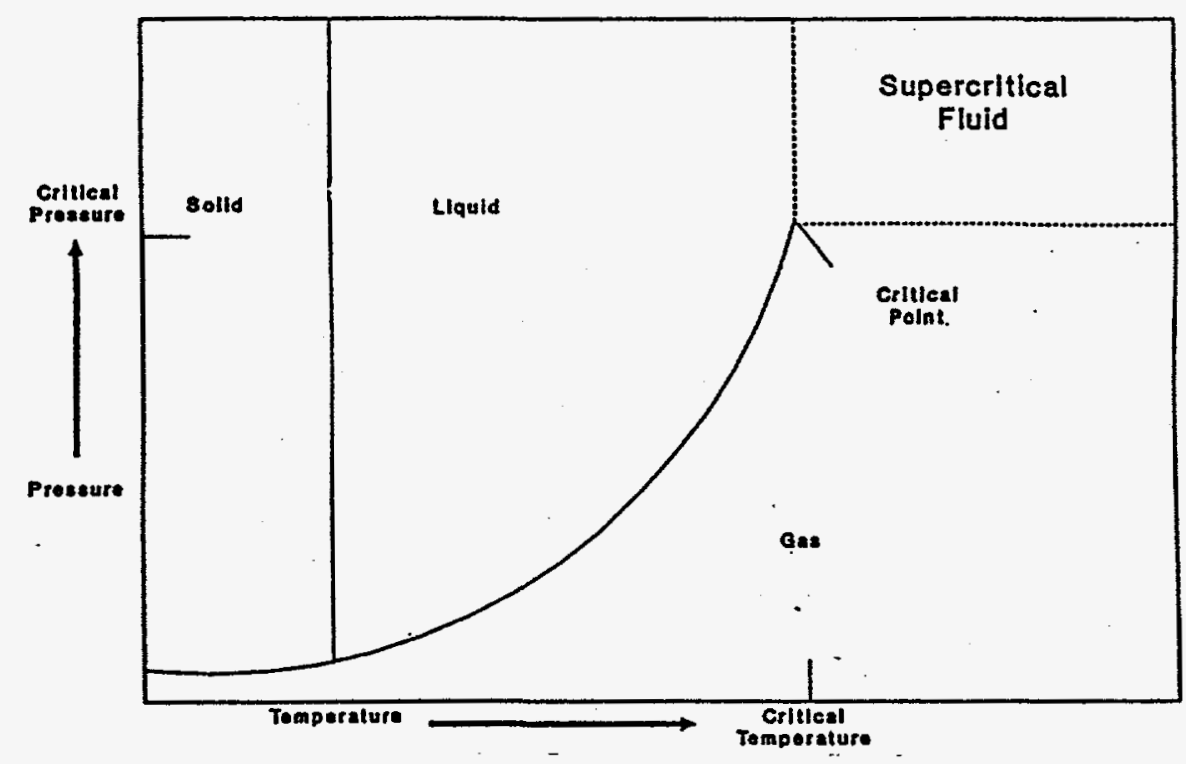

Fig. 1. Phase Diagram

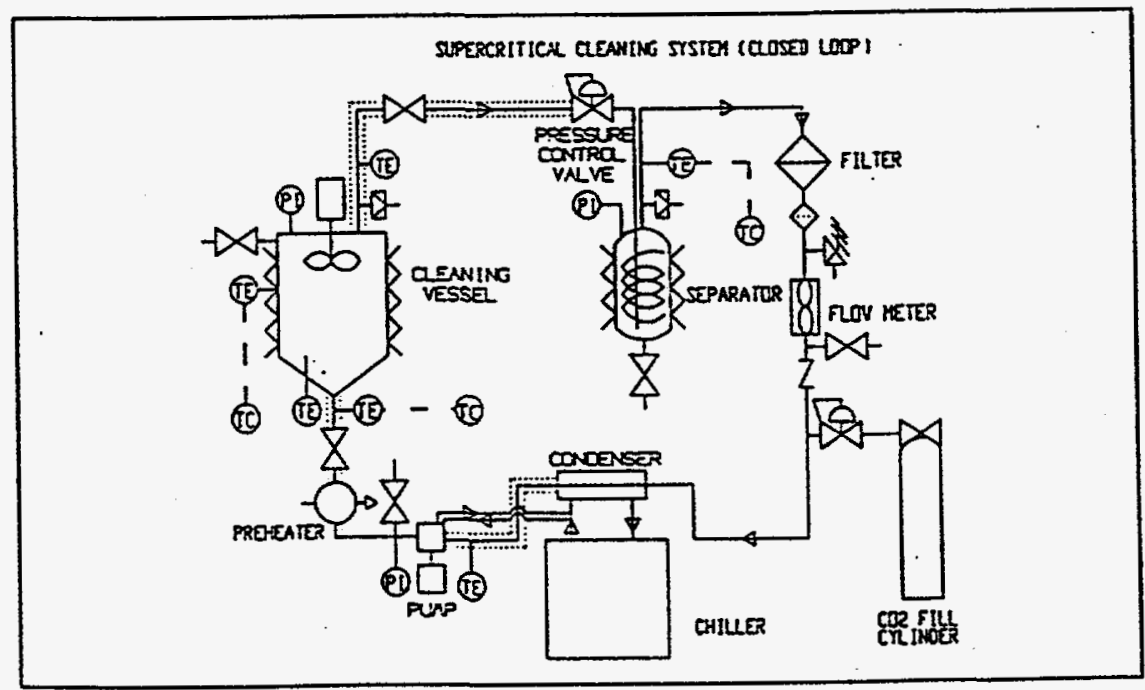

Fig. 2. Supercritical Cleaning System. 


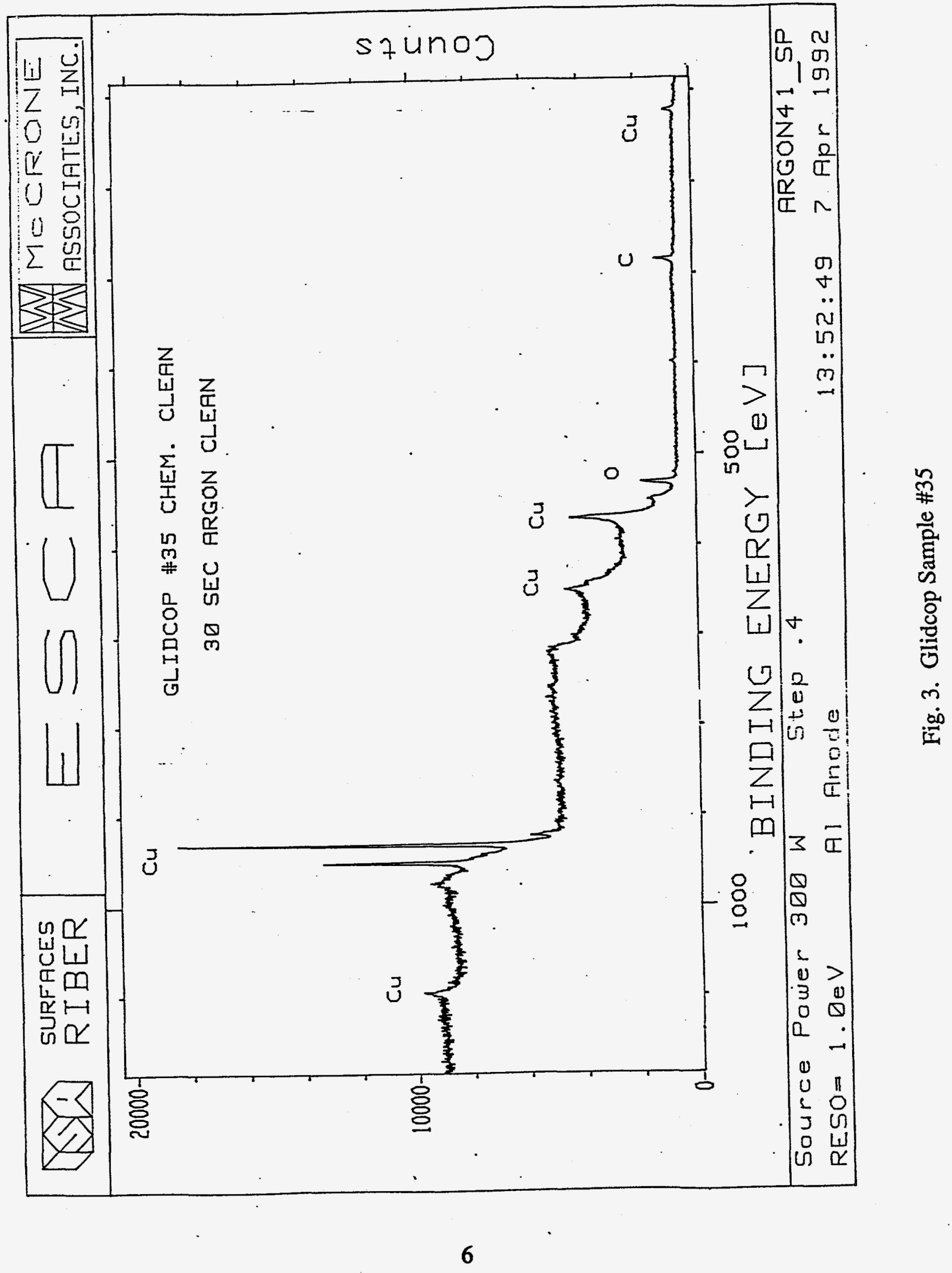




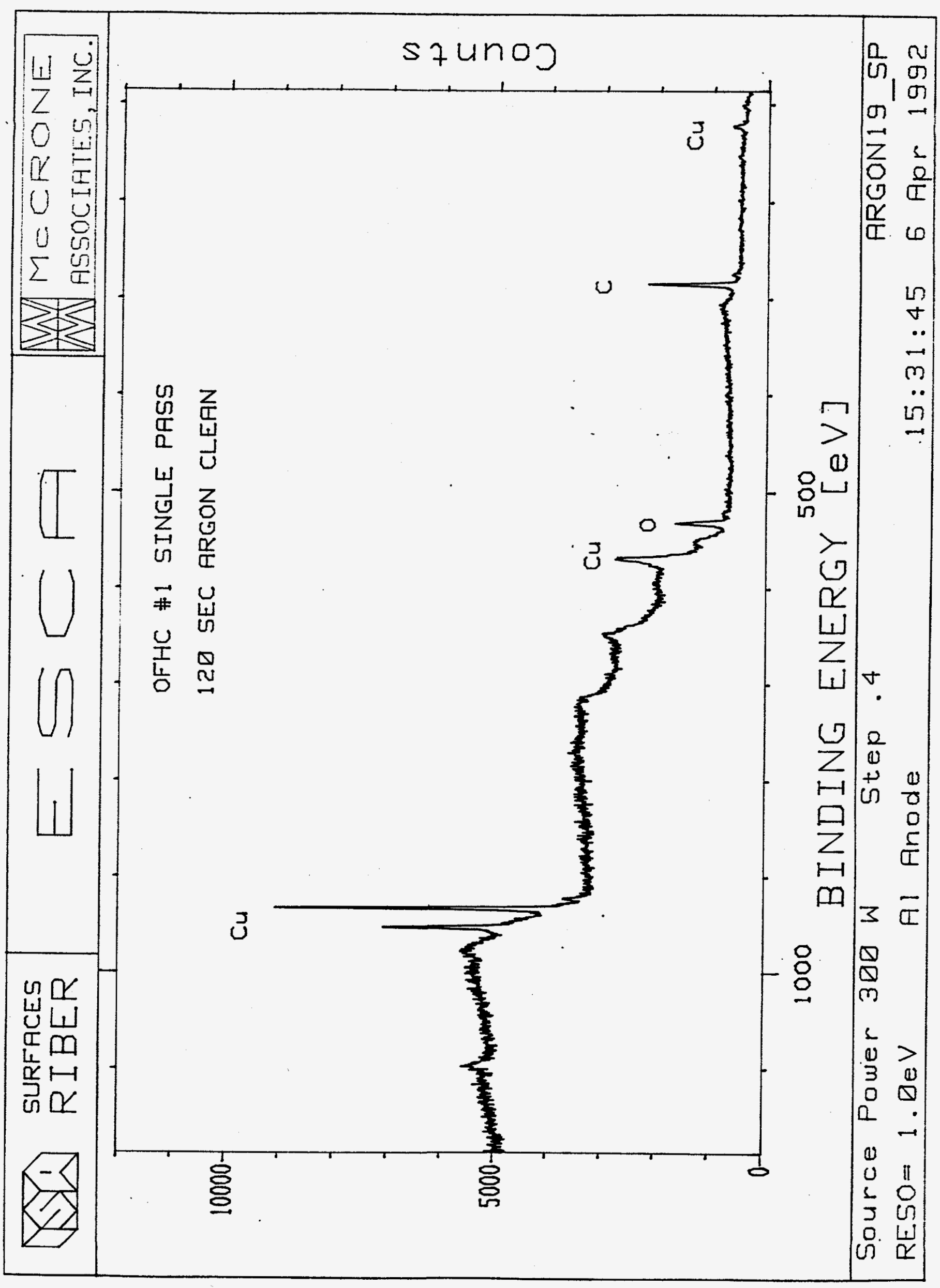




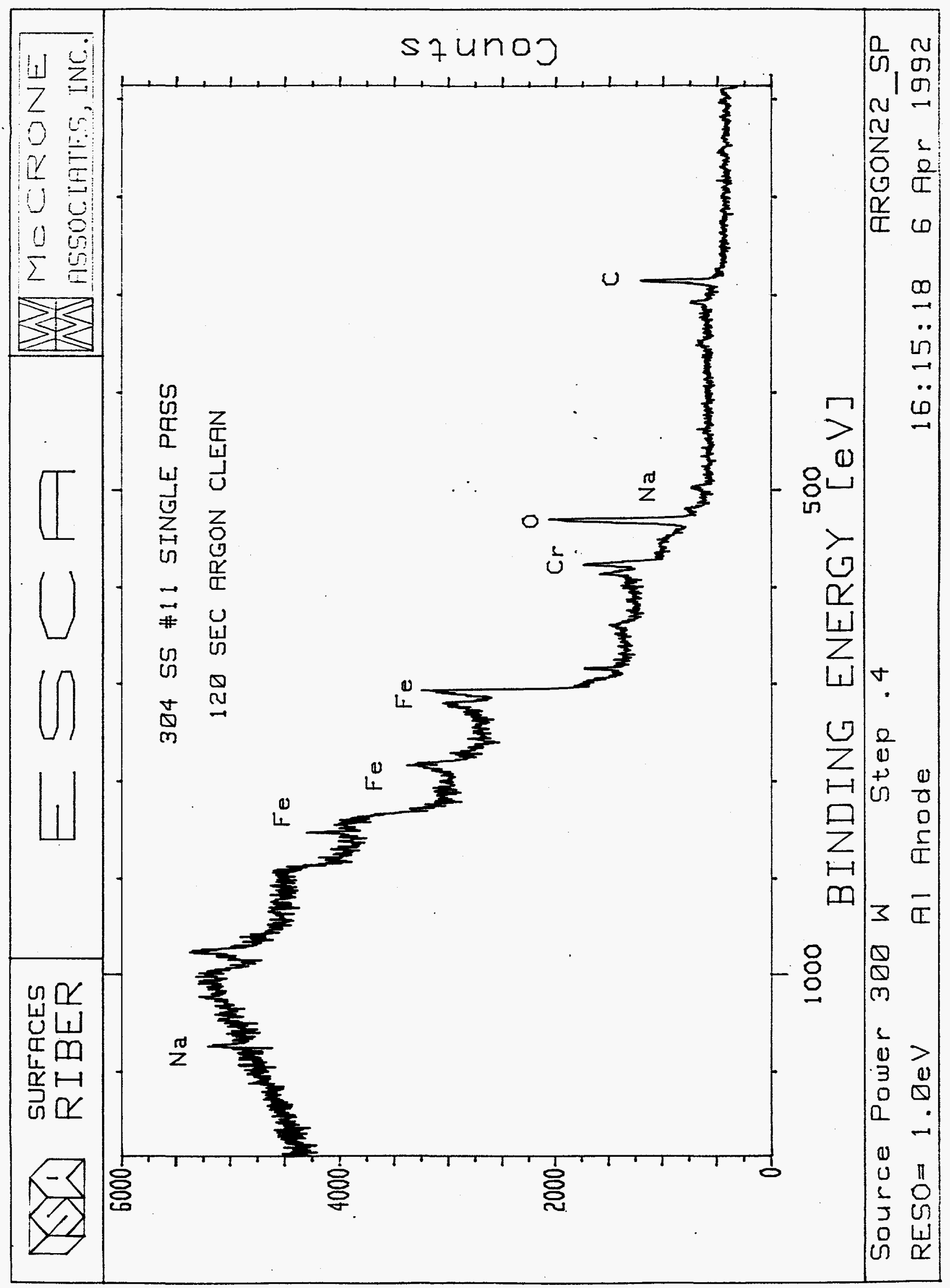




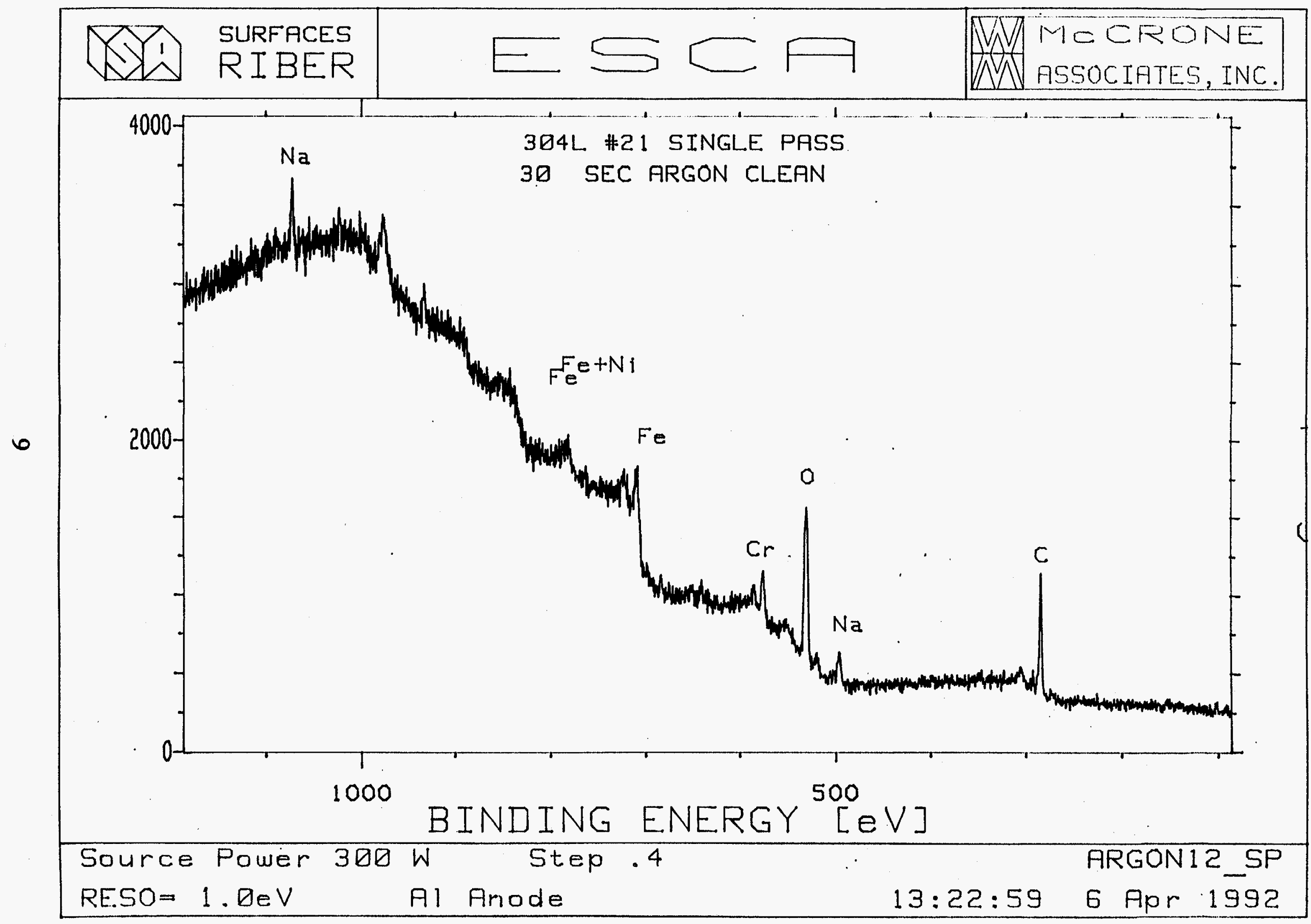

Fig. 6. 304L SS Samnle \#21 
Fig. 7.

\section{Elemental Atomic Percentages on Sample Surfaces-}

\begin{tabular}{|c|c|c|c|c|c|c|c|c|c|c|}
\hline Material & Cleaning Data & $\mathrm{Fe}$ & $\mathrm{Ni}$ & $\mathrm{Cu}$ & $\mathrm{Cr}$ & 0 & C & $\mathrm{Ca}$ & $\mathrm{Na}$ & Si \\
\hline 304 SS \#14 & Uncleaned & & & & & 43.1 & 51.1 & & 5.7 & \\
\hline $\begin{array}{l}304 \text { SS \#11 } \\
\text { Run } 1 \\
3500 \text { psi }\end{array}$ & $\begin{array}{l}\text { SCC Single Pass } \\
\text { SCC Single Pass } 30 \mathrm{Arg} . \mathrm{Cl} \text {. } \\
\text { SCC Single Pass } 120 \mathrm{Arg} . \mathrm{Cl} \text {. }\end{array}$ & $\begin{array}{l}15.3 \\
34.5 \\
43.8\end{array}$ & $\begin{array}{l}5.2 \\
5.6\end{array}$ & & $\begin{array}{r}13 \\
16.2 \\
13.6\end{array}$ & $\begin{array}{r}49 \\
30.9 \\
26\end{array}$ & $\begin{array}{r}19.1 \\
10.3 \\
7.2\end{array}$ & 1.3 & $\begin{array}{l}3.6 \\
2.9 \\
2.4\end{array}$ & \\
\hline $\begin{array}{l}304 \text { SS \#12 } \\
\text { Run } 2 \\
2000 \text { psi }\end{array}$ & $\begin{array}{l}\text { SCC Single Pass } \\
\text { SCC Single Pass } 30 \mathrm{Arg} . \mathrm{Cl} . \\
\text { SCC Single Pass } 120 \mathrm{Arg} . \mathrm{Cl} \text {. }\end{array}$ & $\begin{array}{r}18 \\
33.6 \\
40.8\end{array}$ & $\begin{array}{l}1.2 \\
4.5 \\
5.5\end{array}$ & & $\begin{array}{l}10.5 \\
14.2 \\
15.4\end{array}$ & $\begin{array}{l}46.6 \\
31.3 \\
27.8\end{array}$ & $\begin{array}{r}20.2 \\
10.6 \\
7.3\end{array}$ & $\begin{array}{l}0.1 \\
1.1 \\
0.7\end{array}$ & $\begin{array}{l}3.4 \\
4.7 \\
2.5\end{array}$ & \\
\hline 304 SS \#15 & $\begin{array}{l}\text { Chemical Clean } \\
\text { Chemical Clean } 30 \mathrm{Arg} . \mathrm{Cl} \text {. }\end{array}$ & $\begin{array}{l}42.2 \\
48.6\end{array}$ & $\begin{array}{l}5.1 \\
6.5\end{array}$ & & $\begin{array}{l}15.9 \\
14.5\end{array}$ & $\begin{array}{r}30 \\
29.4\end{array}$ & $\begin{array}{r}5.6 \\
1\end{array}$ & & 1.1 & \\
\hline \multirow{2}{*}{$\begin{array}{l}304 L \text { SS } \\
\# 24\end{array}$} & Uncleaned & & & & & 35.5 & 64.5 & & & \\
\hline & Uncleaned $120 \mathrm{Arg} . \mathrm{Cl}$. & & & & & 19.9 & 72.1 & & 8 & \\
\hline $\begin{array}{l}304 \mathrm{~L} \text { SS } \\
\# 21\end{array}$ & SCC Single Pass & & & · & & 57.1 & 31.9 & & 11 & \\
\hline $\begin{array}{l}\text { Run } 1 \\
3500 \text { psi }\end{array}$ & $\begin{array}{l}\text { SCC Single Pass } 30 \text { Arg. Cl. } \\
\text { SCC Single Pass } 120 \text { Arg. Cl. }\end{array}$ & $\begin{array}{l}35.2 \\
38.9\end{array}$ & $\begin{array}{l}4.7 \\
5.7\end{array}$ & & $\begin{array}{l}11.6 \\
13.5\end{array}$ & $\begin{array}{l}31.6 \\
29.6\end{array}$ & $\begin{array}{r}12.1 \\
6.3\end{array}$ & 1.6 & $\begin{array}{l}4.8 \\
4.4\end{array}$ & \\
\hline $\begin{array}{l}304 L \text { SS } \\
\# 23\end{array}$ & SCC Single Pass & 12.8 & 1.6 & & 9.9 & 52.4 & 19.2 & & 4.1 & \\
\hline $\begin{array}{l}\text { Run } 2 \\
2000 \text { psi }\end{array}$ & $\begin{array}{l}\text { SCC Single Pass } 10 \mathrm{Arg} . \mathrm{Cl} \text {. } \\
\text { SCC Single Pass } 30 \mathrm{Arg} . \mathrm{Cl} \text {. } \\
\text { SCC Single Pass } 120 \mathrm{Arg} . \mathrm{Cl} \text {. }\end{array}$ & $\begin{array}{l}34.5 \\
38.9 \\
43.3\end{array}$ & $\begin{array}{l}4.7 \\
4.8 \\
5.2\end{array}$ & & $\begin{array}{r}9.1 \\
10.5 \\
14.7\end{array}$ & $\begin{array}{l}36.2 \\
30.2 \\
29.1\end{array}$ & $\begin{array}{r}12.3 \\
13.2 \\
5.5\end{array}$ & & $\begin{array}{l}3.2 \\
2.5 \\
2.2\end{array}$ & \\
\hline \multirow{2}{*}{$\begin{array}{l}304 \text { L SS } \\
\# 25\end{array}$} & Chemical Clean & 31.2 & 4.2 & & 13.2 & 42.7 & 8 & 0.7 & & \\
\hline & Chemical Clean $30 \mathrm{Arg} . \mathrm{Cl}$. & 50.6 & 6.4 & & 13.2 & 28.6 & 1.1 & & & \\
\hline OFHC \#5 & Uncleaned & & & 65.4 & & 21.3 & 13.3 & & & \\
\hline $\begin{array}{l}\text { OFHC \#1 } \\
\text { Run } 1 \\
3500 \text { psi }\end{array}$ & $\begin{array}{l}\text { SCC Single Pass } \\
\text { SCC Single Pass } 30 \mathrm{Arg} . \mathrm{Cl} \text {. } \\
\text { SCC Single Pass } 120 \mathrm{Arg} . \mathrm{Cl} \text {. }\end{array}$ & & & $\begin{array}{r}49 \\
86.2 \\
91.6\end{array}$ & & $\begin{array}{r}30.6 \\
8.3 \\
4.3\end{array}$ & $\begin{array}{r}12.9 \\
5.5 \\
4.1\end{array}$ & & & 7.5 \\
\hline $\begin{array}{l}\text { OFHC \#3 } \\
\text { Run } 2 \\
2000 \text { psi }\end{array}$ & $\begin{array}{l}\text { SCC Single Pass } \\
\text { SCC Single Pass } 30 \mathrm{Arg} . \mathrm{Cl} \text {. } \\
\text { SCC Single Pass } 120 \mathrm{Arg} . \mathrm{Cl} \text {. }\end{array}$ & & & $\begin{array}{l}60.5 \\
91.2 \\
94.4\end{array}$ & & $\begin{array}{r}27.9 \\
6 \\
3.8\end{array}$ & $\begin{array}{r}11.6 \\
2.8 \\
1.9\end{array}$ & & & \\
\hline Material & Cleaning Data & $\mathrm{Fe}$ & $\mathrm{Ni}$ & $\mathrm{Cu}$ & $\mathrm{Cr}$ & 0 & C & $\mathrm{Ca}$ & $\mathrm{Na}$ & $\mathrm{Si}$ \\
\hline OFHC \#6 & Chemical Clean & & & 90.8 & & 7 & 2.2 & & & \\
\hline
\end{tabular}


Fig. 7.

Chemical Clean 30 Arg. Cl.

Chemical Clean $120 \mathrm{Arg}$. Cl.

Glidcop \#34 Uncleaned

Glidcop \#31

Run 1

$3500 \mathrm{psi}$

Glidcop \#33

Run 2

2000 psi

Glidcop \#35

SCC Single Pass

SCC Single Pass 30 Arg. Cl.

SCC Single Pass 120 Arg. $\mathrm{Cl}$.

SCC Single Pass

SCC Single Pass $30 \mathrm{Arg} . \mathrm{Cl}$.

SCC Single Pass 120 Arg. $\mathrm{Cl}$.

Chemical Clean $30 \mathrm{Arg} . \mathrm{Cl}$.
97.2

98.5

$2.4 \quad 0.4$

$\begin{array}{ll}1.4 & 0.2\end{array}$

28.6

$27.1 \quad 35.5$

8.8

48.4

90.2

95

$30.5 \quad 17.6$

$5.1 \quad 4.7$

$2.7 \quad 2.3$

50.8

91.3

96.6

$30.4 \quad 13.3$

$5.1 \quad 3.2$

$1.8 \quad 1.6$

72.7

96.6

$21.1 \quad 6.2$

$\begin{array}{ll}2.7 & 0.7\end{array}$

\section{5}

0.5

Notes Run 1 was supercrically cleaned for 1 hour at $45 \mathrm{deg} . C$ at a pressure of 3500 psi with a flow rate of $1.4 \mathrm{~cm} / \mathrm{min}$.

Run 2 was supercritically cleaned for 1 hour at 45 deg. $C$ at a pressure of 2000 psi with a flow rate of $1.6 \mathrm{~cm} / \mathrm{min}$.

Single pass designates $\mathrm{CO}_{2}$ passes sample 1 time and is then exhausted to atmosphere.

Chemical cleaning consisted of uttrasonic cleaning for $15 \mathrm{~min}$ in each of trichlorethane, acetone and ethyl alcohol at room temperature.

$30 \mathrm{Arg}$. Cl. denotes sample was Argon ion etched in ESCA chamber for $30 \mathrm{sec}$ to remove airborn surface contamination from stored samples. 